\title{
On US politics and IMF lending
}

Andersen, Thomas Barnebeck; Harr, Thomas; Tarp, Finn

Published in:

European Economic Review

Publication date:

2006

Citation for published version (APA)

Andersen, T. B., Harr, T., \& Tarp, F. (2006). On US politics and IMF lending. European Economic Review, 50(7). 


\section{Editorial Manager(tm) for European Economic Review \\ Manuscript Draft}

Manuscript Number: EER-D-04-00836R1

Title: On US Politics and IMF Lending

Article Type: FLA Normal Paper

Section/Category:

Keywords: IMF lending; Political factors

Corresponding Author: Dr. Thomas Barnebeck Andersen, PhD

Corresponding Author's Institution: university of copenhagen

First Author: thomas b. andersen, $\mathrm{PhD}$

Order of Authors: thomas b. andersen, PhD; thomas harr, PhD; finn tarp, PhD

Manuscript Region of Origin:

Abstract: The political factors shaping IMF lending to developing countries have attracted attention in recent empirical work. This goes in particular for the role and influence of the US. However, scant formal modelling makes interpretation of empirical results difficult. In this paper, we propose a model in which the US acts as principal within the IMF and seeks to maximize its impact on the policy stance of debtor countries. We derive an optimal loan allocation mechanism, which leads to the testable hypothesis that the probability of an IMF loan is increasing in the amount of political concessions countries make. A political concession is defined as the distance between a country's bliss point and its actual policy stance measured relative to the US. We introduce a bliss-point proxy and demonstrate that our hypothesis is strongly supported in the data. Moreover, we show that not accounting for bliss points may lead to endogeneity bias in empirical work. 
The political factors shaping IMF lending to developing countries have attracted attention in recent empirical work. This goes in particular for the role and influence of the US. However, scant formal modelling makes interpretation of empirical results difficult. In this paper, we propose a model in which the US acts as principal within the IMF and seeks to maximize its impact on the policy stance of debtor countries. We derive an optimal loan allocation mechanism, which leads to the testable hypothesis that the probability of an IMF loan is increasing in the amount of political concessions countries make. A political concession is defined as the distance between a country's bliss point and its actual policy stance measured relative to the US. We introduce a bliss-point proxy and demonstrate that our hypothesis is strongly supported in the data. Moreover, we show that not accounting for bliss points may lead to endogeneity bias in empirical work. 


\title{
On US Politics and IMF Lending*
}

\author{
Thomas Barnebeck Andersen ${ }^{\dagger} \quad$ Thomas Harr Finn Tarp \\ Institute of Economics, University of Copenhagen
}

First version: November, 2003; This version: April, 2005

\begin{abstract}
The political factors shaping IMF lending to developing countries have attracted attention in recent empirical work. This goes in particular for the role and influence of the US. However, scant formal modelling makes interpretation of empirical results difficult. In this paper, we propose a model in which the US acts as principal within the IMF and seeks to maximize its impact on the policy stance of debtor countries. We derive an optimal loan allocation mechanism, which leads to the testable hypothesis that the probability of an IMF loan is increasing in the amount of political concessions countries make. A political concession is defined as the distance between a country's bliss point and its actual policy stance measured relative to the US. We introduce a bliss-point proxy and demonstrate that our hypothesis is strongly supported in the data. Moreover, we show that not accounting for bliss points may lead to endogeneity bias in empirical work.
\end{abstract}

JEL classification: F33; F34; O1; Keywords: IMF lending; Political factors

*We would in particular like to thank Henrik Hansen for numerous valuable comments. In addition, we thank Tony Addison, Henrik Jensen, Thomas Markussen, Pascalis Raimondos-Møller, Klaus Reiner Schenk-Hoppé, Christian Schultz, Birgitte Sloth and Niels Thygesen for valuable criticism. We also thank participants in seminars at Lund University, the University of Copenhagen and the Third Nordic Conference on Development Economics in Gothenburg for useful comments. The usual caveats apply.

${ }^{\dagger}$ Correspondence to Thomas Barnebeck Andersen, Institute of Economics, University of Copenhagen, Studiestræde 6, DK-1455, Copenhagen K, Denmark; Email: Thomas.Barnebeck.Andersen@econ.ku.dk 


\section{Introduction}

Countries in need of an arrangement with the International Monetary Fund (IMF or Fund) typically approach the Fund once alternative ways of financing balance-of-payments deficits are no longer available. The need of borrower countries for Fund arrangements is therefore likely to respond to a variety of economic factors (Knight and Santaella, 1997; Goldstein and Montiel, 1986; Bird, 1995 \& 1996). On the other hand, the granting of IMF loans depends on Fund willingness to approve an arrangement on the basis of the economic stabilization program put forward. Hence, IMF lending is, as demonstrated by Knight and Santaella (1997), a joint outcome of economic demand and supply factors.

Moving beyond the economic determinants of IMF lending, claims have over the years been made based on anecdotal evidence that political factors play a critical role in determining whether countries are successful in obtaining IMF loans or not; and the particular role and influence of the US on IMF behavior has attracted much attention. Calomiris (2000) provides two interesting recent examples: ${ }^{1}$

"Ecuador has been suffering a deepening fiscal crisis for several years caused by the combination of an unresolved internal policy struggle, adverse economic shocks to its terms of trade, and a poorly regulated banking system [...]. As yet, there is no consensus for reform in Ecuador, and there is no reason to believe that reforms will be produced by a few hundreds of millions of IMF dollars. Why in the world is the IMF sending money to Ecuador? Some observes claim that IMF aid to Ecuador is best understood as a means of sending political payola to the Ecuadorian government at a time when the United States wishes to ensure continuing use of its military bases there monitoring drug traffic." (p. 88).

\footnotetext{
${ }^{1}$ See Killick (1995) for earlier case-study based evidence.
} 
"A knowledgeable insider informs me that the U.S. government has told Pakistan that its access to IMF subsidized lending depends on its willingness to sign a nuclear nonproliferation treaty. According to this person, unless Pakistan agrees, the U.S. will block its IMF program." (p. 99).

Moreover, the Meltzer Commission (2000) implicitly accepts the view that G7 governments, particularly the US, use the IMF as a vehicle to achieve own political ends (see also Bird and Rowlands, 2001). This is feasible since voting power in the IMF Executive Board is based on the size of the quotas of member countries. The US holds around $17 \%$ of the votes, and this in effect gives the US veto power over all decisions requiring so-called special voting majority (85\%). In addition, the US Executive Director is appointed by the American Government and is obliged by law to clear his or her decisions with the US Secretary of the Treasury (Oatley and Yackee, 2000).

Econometric studies of the role of political factors in the decision making of the IMF have also started to emerge. Examples include Thacker (1999), Bird and Rowlands (2001) and Barro and Lee (2002). The common characteristic of these papers is that they specify empirical models based on a long list of potential explanatory variables, and they all conclude that political and institutional factors, including US influence, matter and add to our understanding of Fund lending. ${ }^{2}$ However, none of the papers provide any formal theoretical model of the rationale governing the allocation of IMF loans. ${ }^{3}$

Consider the seminal and widely quoted paper by Thacker (1999). He hypothesizes that IMF lending is influenced by political "proximity" between the potential borrower and the US on key political matters, as well as by political "movement" towards the US policy

\footnotetext{
${ }^{2}$ Dreher and Jensen (2004) analyze whether political relations with the US have any bearing on IMF conditionality. Interestingly, they find that a debtor country's relationship with the US influences the number of conditions the IMF imposes on a the country.

${ }^{3}$ Bird and Rowlands (2003), for example, call for "a better understanding of precisely what the political economy variables are, and the modalities through which the exert their influence".
} 
position in these matters. ${ }^{4}$ Proximity is found to be statistically significant, but only at the $10 \%$ level. ${ }^{5}$ In contrast, movement is significant at the $1 \%$ level. Thacker concludes that potential borrower countries are rewarded if they move closer to the US political position regardless of absolute alignment. Yet, the lack of a formal theoretical underpinning makes Thacker's results difficult to interpret: Why should the US reward a country taking a position close to the US stance if that particular country would have done so regardless of any reward?

In the stylized model put forward in this paper, the empirical implications of the US maximizing its overall influence on the policy stance of IMF member countries are derived. ${ }^{6}$ The IMF loan allocation problem is posed as a mechanism design problem. We solve for an optimal mechanism in which the US allocates IMF loans through an all-pay auctiontype mechanism, where loan allocation probabilities are increasing in the size of political concessions. Political concessions are defined as the difference between a country's actual policy position and its true political preferences, both measured relative to the US position. ${ }^{7}$ True political preferences are identified as bliss points in a policy space ranging from no to complete alignment with the US. Actual positions are measured in the same policy space.

Our theoretical framework suggests that neglecting bliss points can lead to endogeneity problems. This is potentially important since all previous studies to our knowledge neglect bliss points. Relying on some measure of proximity on important issues, not the difference between proximity and bliss points, is problematic, since theoretically these two variables are correlated; any a priory consistent empirical test must either construct a proxy variable for the bliss points or rely on a fixed-effects approach to eliminate unobserved heterogeneity.

\footnotetext{
${ }^{4}$ Political proximity is captured by a variable constructed from data on voting in the United Nations General Assembly, and movement is calculated as the change in this variable.

${ }^{5}$ This finding is echoed by Barro and Lee (2002) and Oatley and Yackey (2000). However, by using a different measure of proximity than Thacker (1999), the interpretation is different. We will return to this point in Section 3.

${ }^{6}$ Some argue that the interests of private financial institutions (especially US financial institutions) also influence the decisions of the IMF (see Gould, 2003 and Oatley and Yackee, 2000). While concurring with the main trust of this argument, we do not pursue this type of influence here.

${ }^{7}$ True political preferences are taken as a primitive datum.
} 
Opting for the former approach, we introduce an empirical proxy for the bliss points and test our model using Thacker's baseline empirical specification. Our hypothesis finds strong support in both the Thacker data (1985-1994) and in an extended dataset covering 19952000. In sum, both our theoretical model and the empirical results indicate that bliss points should be taken into account. Moreover, by demonstrating that the data are consistent with maximizing behavior, our paper strengthens the thesis that political factors play a decisive role in IMF lending decisions.

The rest of the paper is structured as follows: Section 2 provides the model and solves for the optimal mechanism. In Section 3, we derive empirical implications and test the model. Conclusions are offered in Section 4.

\section{The Model}

\subsection{The set-up}

Suppose that $N$ countries from the set $\mathcal{N}=\{1, . ., N\}$ are competing for the allocation of an IMF loan, and assume that the US plays the role of principal within the IMF. ${ }^{8}$ Further, assume that the US designs a loan allocation mechanism, which maximizes the degree of alignment with its position on key foreign policy issues. Let $b_{i} \in[0,1]$ be the true preferences of country $i$ relative to the US (country $i$ 's bliss point), with the US bliss point equal to 1 . Also, let the $b_{i}$ 's be publicly observable. A given country can take a position $p_{i} \in[0,1]$, where $p_{i}=1$ indicates complete alignment with the US. Let $t_{i}=p_{i}-b_{i}$ be the political concession (henceforth political payment) country $i$ can offer in exchange for a loan allocation probability. The total amount of political payments achieved by the US therefore equals $\sum_{i=1}^{N} t_{i}$

\footnotetext{
${ }^{8}$ At first glance, the assumption of just one loan seems restrictive since in reality the IMF allocates several loans. One way to rationalize this is to think of a situation where all but one loan are allocated according to economic criteria, and then the last loan is allocated by US discretion.
} 
Fig. 1 illustrates the setup. The maximum political payment country $i$ can offer is given by $w_{i}=1-b_{i}$. Countries therefore face a constraint on their political payments. The closer country $i$ 's true preferences are to the US position, the less there is to offer and pay in terms of political concessions.

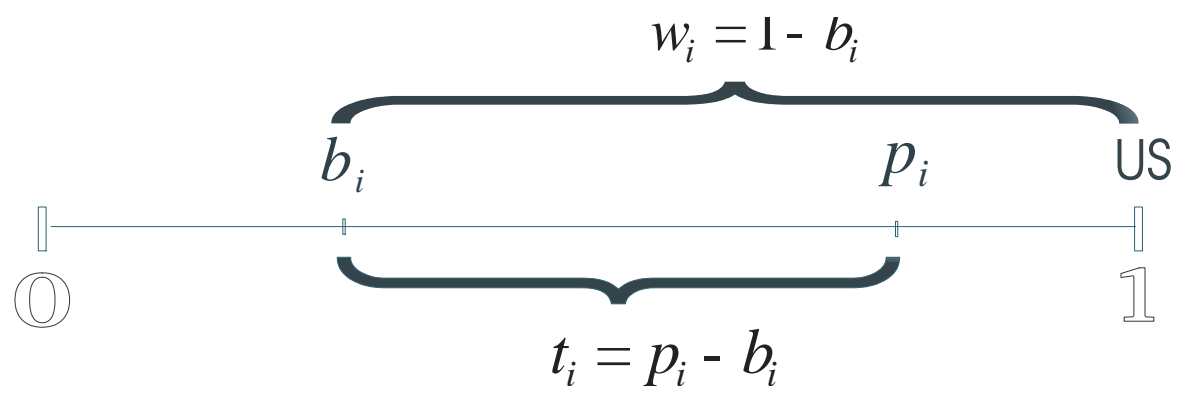

Fig. 1. The policy space

Turning to the specification of country utility, assume that all countries are risk neutral with expected utility given by

$$
u_{i}=\theta_{i} x_{i}-t_{i} \quad(i \in \mathcal{N})
$$

where $x_{i} \in[0,1]$ is the probability that country $i$ receives the loan to be allocated, $\theta_{i}$ is country $i$ 's valuation of the loan, and $t_{i} \in[0,1]$ is the expected political payment. ${ }^{9}$ For simplicity we take the US valuation of the IMF loan to be zero, and this is common knowledge among countries. In contrast, $\theta_{i} \in[\underline{\theta}, \bar{\theta}] \equiv \Theta \subseteq[0,1]$ is private information. We take the $\theta_{i}$ 's to be identically and independently distributed according to the distribution function $F(\cdot)$,

\footnotetext{
${ }^{9}$ We restrict attention to $t_{i} \in[0,1]$ since in equilibrium political payments are always nonnegative. Alternatively, we could have used $t_{i} \in[-1,1]$ and $u_{i}=\theta_{i} x_{i}-\left|t_{i}\right|$.
} 
which is assumed to be continuously differentiable with density $f(\cdot)$ and bounded below by a strictly positive number. Finally, the problem is assumed to be regular. ${ }^{10}$

It follows that in order to maximize its overall political influence, the US has to design a loan allocation mechanism that maximizes $\sum_{i=1}^{N} t_{i}$, taking into account the constraints on the size of political payments that individual countries face. ${ }^{11}$

\subsection{The optimal Bayesian mechanism}

In deriving the optimal mechanism, two simplifying steps are useful. First, we invoke the revelation principle (Myerson, 1981), and secondly, we show that the constraints on political payments imply that attention can be restricted to all-pay mechanisms. The revelation principle gives that the US can restrict attention to feasible direct revelation mechanisms, where feasibility refers to constraints on individual rationality, incentive compatibility, and resources (i.e. constraints on the $x_{i}$ 's).

A direct mechanism is summarized by the functions

$$
\left\langle\left(x_{i}\left(\theta_{i}, \theta_{-i}\right)\right), t_{i}^{W}\left(\theta_{i}, \theta_{-i}\right), t_{i}^{L}\left(\theta_{i}, \theta_{-i}\right)\right\rangle_{i \in \mathcal{N}}
$$

where $t_{i}^{W}\left(\theta_{i}, \theta_{-i}\right)$ is the political payment by country $i$ if it gets the loan and $t_{i}^{L}\left(\theta_{i}, \theta_{-i}\right)$ is the payment when it does not get the loan. The US solves for the optimal feasible direct revelation mechanism:

$$
\max _{\left(x_{i}(\cdot), t_{i}^{W}(\cdot), t_{i}^{L}(\cdot)\right)} E_{\theta}\left[\sum_{i \in \mathcal{N}}\left(x_{i}\left(\theta_{i}, \theta_{-i}\right) t_{i}^{W}\left(\theta_{i}, \theta_{-i}\right)+\left(1-x_{i}\left(\theta_{i}, \theta_{-i}\right)\right) t_{i}^{L}\left(\theta_{i}, \theta_{-i}\right)\right)\right]
$$

\footnotetext{
${ }^{10}$ The problem is regular if the virtual valuation $\psi(\theta)=\theta-(1-F(\theta)) / f(\theta)$ is increasing in $\theta$ (Krishna, 2002).

${ }^{11}$ Our framework could be further developed by taking into account the fact that countries, which are close to the US in terms of bliss points, could be at risk of moving further away from the US position if an IMF arrangement does not materialize (by a change in government, say). We leave this added complication for future research.
} 
subject to

$$
\begin{gathered}
E_{\theta_{-i}}\left[x_{i}\left(\theta_{i}, \theta_{-i}\right)\left(\theta_{i}-t_{i}^{W}\left(\theta_{i}, \theta_{-i}\right)\right)-\left(1-x_{i}\left(\theta_{i}, \theta_{-i}\right)\right) t_{i}^{L}\left(\theta_{i}, \theta_{-i}\right)\right] \geq \\
E_{\theta_{-i}}\left[x_{i}\left(\theta_{i}^{\prime}, \theta_{-i}\right)\left(\theta_{i}-t_{i}^{W}\left(\theta_{i}^{\prime}, \theta_{-i}\right)\right)-\left(1-x_{i}\left(\theta_{i}^{\prime}, \theta_{-i}\right)\right) t_{i}^{L}\left(\theta_{i}^{\prime}, \theta_{-i}\right)\right] \\
\left(\forall i \in \mathcal{N}, \forall\left(\theta_{i}, \theta_{i}^{\prime}\right) \in \Theta^{2}\right), \\
E_{\theta_{-i}}\left[x_{i}\left(\theta_{i}, \theta_{-i}\right)\left(\theta_{i}-t_{i}^{W}\left(\theta_{i}, \theta_{-i}\right)\right)-\left(1-x_{i}\left(\theta_{i}, \theta_{-i}\right)\right) t_{i}^{L}\left(\theta_{i}, \theta_{-i}\right)\right] \geq 0 \\
\quad\left(\forall i \in \mathcal{N}, \forall \theta_{i} \in \Theta\right), \\
x_{i}(\theta) \geq 0 \quad\left(\forall i \in \mathcal{N}, \forall \theta \in \Theta^{N}\right) \text { and } \sum_{i \in \mathcal{N}} x_{i}(\theta) \leq 1 \quad\left(\forall \theta \in \Theta^{N}\right), \\
\max \left\{t_{i}^{W}(\theta), t_{i}^{L}(\theta)\right\} \leq w_{i} \quad\left(\forall i \in \mathcal{N}, \forall \theta \in \Theta^{N}\right),
\end{gathered}
$$

where (2) are the incentive compatibility constraints; (3) the individual rationality constraints; (4) the resource constraints; and (5) the constraints on political payments.

Turning now to the second simplifying step, lemma 1 below states that in the presence of observable constraints on political payments, $w_{i}=1-b_{i}$ (equivalently, observable bliss points $b_{i}$ ), attention can always without loss of generality (w.l.o.g.) be restricted to all-pay mechanisms where countries submit non-refundable political payments. ${ }^{12}$

Lemma 1 When countries face publicly observed bliss points, $b_{i}$, attention can always w.l.o.g. be restricted to all-pay mechanisms in which $t_{i}^{W}\left(\theta_{i}, \theta_{-i}\right)=t_{i}^{L}\left(\theta_{i}, \theta_{-i}\right)=t_{i}\left(\theta_{i}\right)$ for $i \in \mathcal{N}$. In fact, all-pay mechanisms weakly revenue dominate any other mechanism.

Proof. See Appendix A.1.

\footnotetext{
${ }^{12}$ Laffont and Roberts (1996) also rely on this second step in their paper. They do not, however, provide a formal proof. The proof of lemma 1 partly relies on arguments in Maskin (2000).
} 
Using lemma 1, the problem of the US, (1) to (5), can be simplified. To see this, note that by lemma 1, country $i$ 's political payment function is independent of whether country $i$ receives the loan or not, and independent of the other country types, but dependent upon country $i$ 's own type. That is, a country makes a non-refundable political payment, which depends only on its own type. We obtain

$$
\max _{x_{i}(\cdot), t_{i}(\cdot)} E_{\theta} \sum_{i \in \mathcal{N}} t_{i}\left(\theta_{i}\right)
$$

subject to

$$
\begin{gathered}
E_{\theta_{-i}}\left[x_{i}\left(\theta_{i}, \theta_{-i}\right)\right] \theta_{i}-t_{i}\left(\theta_{i}\right) \geq E_{\theta_{-i}}\left[x_{i}\left(\theta_{i}^{\prime}, \theta_{-i}\right)\right] \theta_{i}-t_{i}\left(\theta_{i}^{\prime}\right) \quad\left(\forall i \in \mathcal{N}, \forall\left(\theta_{i}, \theta_{i}^{\prime}\right) \in \Theta^{2}\right), \\
E_{\theta_{-i}}\left[x_{i}\left(\theta_{i}, \theta_{-i}\right)\right] \theta_{i}-t_{i}\left(\theta_{i}\right) \geq 0 \quad\left(\forall i \in \mathcal{N} \text { and } \forall \theta_{i} \in \Theta\right), \\
x_{i}(\theta) \geq 0 \quad\left(\forall i \in \mathcal{N} \text { and } \forall \theta \in \Theta^{N}\right) \text { and } \sum_{i \in \mathcal{N}} x_{i}(\theta) \leq 1 \quad\left(\forall \theta \in \Theta^{N}\right), \\
t_{i}\left(\theta_{i}\right) \leq w_{i}, \quad\left(\forall i \in \mathcal{N}, \forall \theta_{i} \in \Theta\right) .
\end{gathered}
$$

Krishna (2002) defines a standard auction as a mechanism which allocates the object to the bidder making the highest offer. The next two propositions provide restrictions on the parameter space, $b_{1} \times \cdots \times b_{N} \times \Theta$, which ensures that the solution to the problem (6) to (10) is a standard auction.

Proposition 2 When all $N$ countries have bliss points sufficiently far away from the US bliss point, i.e. when $\max b_{i} \leq 1-\bar{\theta}$, the optimal mechanism is a standard all-pay auction in which the loan is allocated to the country making the highest political payment.

Proof. See Appendix A.2. 
When $\max b_{i}>1-\bar{\theta}$ (or equivalently, $\min w_{i}<\bar{\theta}$ ), the problem is more complicated. However, Laffont and Robert (1996) have solved (6)-(10) analytically in the symmetric case $\left(b_{i}=b_{j}=b\right)$.

Proposition 3 When all $N$ countries have identical bliss points, i.e. when $b_{i}=b_{j}=b$ for all $i, j \in \mathcal{N}$, the optimal mechanism is a standard all-pay auction in which the loan is allocated to the country making the highest political payment.

Proof. Follows from Laffont and Robert (1996).

Consequently, when $\max b_{i} \leq 1-\bar{\theta}$ and/or $b_{i}=b_{j}=b$, the optimal way for the US to allocate IMF loans is through a standard all-pay auction. Countries submit non-refundable political payments and the country with the highest payment receives the loan.

Turning to the asymmetric case in the unrestricted parameter space, no analytical solution is available. ${ }^{13}$ We therefore proceed to solve numerically the asymmetric problem in the simple two-country case where types are drawn from a Bernoulli distribution.

\subsubsection{A numerical solution}

Let $\operatorname{Pr}\left(\theta_{i}=\bar{\theta}\right)=\nu$ and $\operatorname{Pr}\left(\theta_{i}=\underline{\theta}\right)=1-\nu$, where $0<\underline{\theta}<\bar{\theta}$. The problem (6)-(10) can now be written as a maximization problem for $i=1,2$ in $x_{i}\left(\theta_{1}, \theta_{2}\right)$ for all $\left(\theta_{1}, \theta_{2}\right) \in\{\underline{\theta}, \bar{\theta}\} \times\{\underline{\theta}, \bar{\theta}\}$, and $t_{i}\left(\theta_{i}\right)$ for all $\theta_{i} \in\{\underline{\theta}, \bar{\theta}\}$ (see Appendix A.2).

Before proceeding to the solution, we make the following definition: A mechanism is an auction-type mechanism if the country making the highest political payment stands the highest probability of receiving the loan. That is,

\footnotetext{
${ }^{13}$ When $b_{i}=b_{j}=b$, the analysis is complicated, but manageable (Laffont and Robert, 1996), since symmetry of the strategies can be imposed. Clearly, this is not possible when $b_{i} \neq b_{j}$. Without symmetry we face a highly complex control problem.
} 
Definition 4 The mechanism $\left\langle x_{i}\left(\theta_{1}, \theta_{2}\right), t_{i}\left(\theta_{i}\right)\right\rangle_{i \in\{1,2\}}$ is an auction-type mechanism if

$$
\left(t_{i}\left(\theta_{i}\right)-t_{j}\left(\theta_{j}\right)\right) \cdot\left(x_{i}\left(\theta_{1}, \theta_{2}\right)-x_{j}\left(\theta_{1}, \theta_{2}\right)\right) \geq 0
$$

for all $i, j \in\{1,2\}$ and for all $\left(\theta_{1}, \theta_{2}\right) \in \Theta^{2}$.

Clearly, a standard auction (including the standard all-pay auction), in which the bidder making the highest bid wins, satisfies definition 4 .

Fig. 2 illustrates an optimal all-pay auction-type mechanism. First, it follows immediately from eyeballing the figure that definition 4 is satisfied. Second, the constraint on political payments, $w_{1}=0.3$, is always binding for a high-type country 1 when $v \in(0.438,0.570)$. Country 2 on the other hand does not face a de facto constraint on political payments, since

country 2 will never pay more than $\bar{\theta}=w_{2}$. However, a high-type country 2 does pay $w_{2}$ when $v \in(0.438,0.570)$. Finally, the optimal mechanism does not allocate the loan to a low-type country 2 and a low-type country 1 when $v \geq 0.429$ and $v \geq 0.572$, respectively. In these cases, political payments from low types are zero.

-Insert Fig. 2 here-

Fig. 2: The optimal mechanism with $\bar{\theta}=0.7, \underline{\theta}=0.3, w_{1}=0.3, w_{2}=0.7$

\subsection{A testable hypothesis}

Appendix A.3 reports results from optimizations on 28,000 parameter combinations. We find that in over $97 \%$ of the cases, an all-pay auction-type mechanism is optimal. Moreover, when the conditions in proposition 2 and 3 are met, a standard all-pay auction is always optimal. In all these cases, it is optimal for the US to allocate IMF loans through an all-pay auction-type mechanism. The country that makes the highest political payment stands the 
highest probability of receiving the IMF loan. This is an intuitive result: if the US wants to maximize its overall political influence on IMF member countries, it will reward large political concessions with IMF loans more frequently. This is our testable hypothesis. ${ }^{14}$

It should be noted that our hypothesis is different from the political proximity hypothesis found in Thacker (1999). In our model, proximity with the US foreign policy stand is not necessarily positively correlated with the probability of getting an IMF loan. The following example provides an illustration hereof.

Example 5 Consider the case where $\underline{\theta}=0.3, \bar{\theta}=0.7, w_{1}=0.3, w_{2}=0.7$. This is the scenario in Fig. 2 above. Let $\nu=0.8$ and let both countries be high types. Inspection of Fig. 2 shows that $x_{2}(\bar{\theta}, \bar{\theta})=0.762>x_{1}(\bar{\theta}, \bar{\theta})=0.238$ and $t_{2}(\bar{\theta})=0.567>t_{1}(\bar{\theta})=0.273$. Using $t_{i}=p_{i}-b_{i}$ and $b_{i}=1-w_{i}$, we obtain $p_{1}=0.973>p_{2}=0.867$. Hence, country 1 is voting more in accordance with the US than country 2 , but the former stands a lower chance of receiving the loan.

If, however, bliss points (i.e. true political preferences) are taken into account, we should expect a positive correlation between political payments (i.e. political concessions) and the probability of getting an IMF loan.

Related, Example 5 draws attention to the key point that countries with higher bliss points will, ceteris paribus, take positions closer to the US. This has implications for the empirical analysis in that it introduces an endogeneity problem if we fail to account for bliss points; a point to which we will return in Section 3.1.1 below.

\footnotetext{
${ }^{14}$ On a practical level, the hypothesis that loans are allocated through an (implicit) all-pay auction-type mechanism is appealing, because it is a simple implementable mechanism. In contrast, a mechanism which is not of the auction type would be difficult to implement and thus violate Wilson's simplicity doctrine (see Krishna, 2002).
} 


\section{Empirical Analysis}

We will test our model in two steps. In the first step we rely on the same dataset and the same empirical baseline specification as in Thacker (1999). ${ }^{15}$ This renders a direct comparison between the movement hypothesis and our political-concession hypothesis possible. In the second step, we extend the Thacker data from 1995-2000 and include more countries and more loan types. The Mexican bailout in 1995 was the harbinger of a series of large IMF bailouts; it therefore makes sense to analyze this period and the 1985-1994 period covered by Thacker separately.

\subsection{Testing the model using Thacker's data}

According to Bird and Rowlands (2001, p. 252), Thacker's paper provides "the best example to date of integrating political and economic variables into the analysis of Fund lending". The Thacker dataset consists of annual observations from 83 developing countries during the period 1985 to 1994. The dependent variable is binary and takes a value of 1 for a given country year if the country signed an IMF Stand-by Arrangement (SBA) or an Extended Fund Facility (EFF) during the calendar year, zero otherwise. ${ }^{16}$ Explanatory variables include standard macroeconomic factors, which are expected to affect both the demand for and the supply of IMF loans.

Thacker introduces in addition two political variables in order to capture US influence on IMF lending. The first, kvot $_{i, t-2}$, is a proxy for the political proximity between the sample country and the US on important foreign policy matters (corresponding to $p_{i}$ in our theoretical model). ${ }^{17}$ More specifically, $k v o t e_{i, t-2}$ is measured by the degree of coincidence

\footnotetext{
${ }^{15}$ Strom C. Thacker has made his dataset publicly available at http://www.bu.edu/sthacker/data.html.

${ }^{16} \mathrm{SBA}$ and EFF loans often cover several years, but only the first year is recorded in the dependent variable. Note also that while the IMF uses a variety of instruments in supporting member countries, SBA and EFF are the main IMF arrangements when it comes to short term balance of payments support.

${ }^{17}$ Subscript $i$ refers to country and subscript $t$ to year.
} 
between the votes of the sample country and the US in the United Nations General Assembly (UNGA) on issues, which the US Department of State defines as key votes. These votes are listed in the annual US Department of State publication "Report to Congress on Voting Practices in the United Nations". ${ }^{18}$ The report from 1985 notes that:

"[the] only votes that can legitimately be read as a measure of support for the United States are those which we identified as important to us, and on which we lobbied other nations" (quoted in Thacker, 1999 p. 53).

Moreover, the report from 1997 states that:

"[...] a country's behavior at the UN is always relevant to its bilateral relationship with the United States, a point the Secretary of State regularly makes in letters of instruction to new U.S. ambassadors. This is also why copies of this report are presented to UN member foreign ministries throughout the world, and to observer missions in New York. The Security Council and the General Assembly are arguably the most important international bodies in the world, dealing as they do with such vital issues as threats to peace and security, disarmament, development, humanitarian relief, human rights, the environment and narcotics - all of which can and do directly affect major U.S. interest." (p. 6). ${ }^{19}$

The proxy kvote $_{i, t-2}$ is calculated as a number between 0 and 1 , where ascending values indicate higher degrees of alignment with the US. ${ }^{20}$

\footnotetext{
${ }^{18}$ The report is addressed to the President of the Senate and to the Speaker of the House of Representatives, and it is signed by the Secretary of State. Ultimately then, it is the Secretary of State who endorses the identification of key votes.

${ }^{19}$ As an example, key votes in 1993 inter alia cover issues concerning the non-compliance of Iraq and North Korea with safeguards agreement on the use of nuclear energy for peaceful purposes; the US trade embargo of Cuba; a call for an Israeli withdrawal from the Golan Heights; and Israeli nuclear armament.

${ }^{20}$ Thacker assigned a value of 1 to votes in agreement with the US, whereas votes in disagreement with the US were given 0 value. Abstentions and absences by the sample country were included as 0.5. The justification for assigning 0.5 to nonvotes is that they can be interpreted as neutral votes.
} 
Thacker's second political variable, mkvote $_{i, t-1}$, captures political movement. It is defined as mkvote $_{i, t-1}=$ kvote $_{i, t-1}-$ kvote $_{i, t-2}$ and it measures the change in sample country $i$ 's political proximity with the US from year $t-2$ to year $t-1$. The variable belongs to the interval $[-1,1]$, where a positive value reflects that the sample country has moved towards the US position.

\subsubsection{Defining a proxy-variable}

According to our theoretical model, omitting bliss points could result in misspecification, which may have serious consequences for statistical inference. To see this, recall that political concessions, $t_{i}$, are defined as $t_{i}=p_{i}-b_{i}$. Including only $p_{i}$ in an empirical model may well lead to endogeneity bias (unless explicitly addressed) since the omitted $b_{i}$ 's will be captured by the error term, $v_{i}$. Countries with higher bliss points will, ceteris paribus, take positions closer to the US, implying that the error term, $v_{i}$, will be correlated with actual positions, $p_{i}$. That is, $\operatorname{cov}\left(p_{i}, b_{i}\right)>0$ implies that $\operatorname{cov}\left(p_{i}, v_{i}\right)>0$.

One way to correct for endogeneity caused by unobserved heterogeneity is to rely on a proxy-variable approach; another way is to employ a fixed-effects estimator. In this section we take the former approach, but will have more to say on the latter in Section 3.1.3.

Turning to the construction of a bliss-point proxy, note that key votes only constitute a small part of all UNGA resolutions; the bulk of all resolutions is not identified as important by the US State Department. In 1991, which is fairly representative of the sample years, there were 88 plenary votes (74 on resolutions, 10 on separate paragraphs, two on decisions, and two on motions); only 12 of these plenary votes were identified as key votes. On the 76 non-key votes, countries are in our view likely to vote in accordance with their true political preferences since the US is not exercising pressure. The majority of UNGA votes thus provide information on countries' bliss points.

We employ a spatial measure, $S_{i, t}$, proposed by Signorino and Ritter (1999), to project 
the UNGA votes into a single index measure. Gartzke and Jo (2002) have undertaken the considerable task of compiling $S_{i, t}$ from all votes in the UNGA, and they have made their computations publicly available. ${ }^{21}$ The Gartzke-Jo computations have subsequently been used in published work related to the present paper by Neumayer (2003) and Stone (2004) to proxy countries' foreign-policy preferences. Hence, public availability and peer acceptance are two desirable features of $S_{i, t}$.

Turning to the specifics of the index measure, $S_{i, t}$ is computed according to $S_{i, t}=$ $1-\sum_{k=1}^{K(t)} w_{k, t}\left|v_{k, t}^{U S}-v_{k, t}^{i}\right|$, where $v_{k, t} \in\{1(=$ "no"), $2(=$ "abstain"), 3 (= "yes") $\}$ is the position taken by a country on vote $k$ in year $t$ in the UNGA, $K(t)$ is the number of votes in year $t$, and $w_{k, t}=\frac{1}{K(t)}$ is the weight attached to vote $k$ in year $t$ (all votes in a given year are thus weighted equally). ${ }^{22}$ We proxy bliss points by bliss $s_{i, t}=\frac{1}{2}\left(1+S_{i, t}\right)$. By construction, $S_{i, t}$ lies in the $[-1,1]$ interval; we have used the normalization to ensure that bliss $_{i, t} \in[0,1]$

Consequently, we define a new variable, bid, as

$$
\begin{aligned}
\text { bid }_{i, t-1} & =\alpha \cdot \text { kvote }_{i, t-1}+(1-\alpha) \cdot \text { kvote }_{i, t-2}-\text { bliss }_{i, t-2} \\
& =\alpha \cdot \text { mkvote }_{i, t-1}+\left(\text { kvote }_{t-2}-\text { bliss }_{i, t-2}\right), \quad \alpha \in[0,1]
\end{aligned}
$$

corresponding to $t=p-b$ in the theoretical model. Some comments on the lag structure are in order. First, voting in the UNGA takes place from September to December. Hence, all IMF loans pertaining to the first two thirds of year $t$ can only rely on voting in year $t-1$. Second, the report to Congress on "Voting Practices in the United Nations", compiling voting behavior for year $t-1$, is released annually on 31 March in year $t$. For some part of year $t$ then, only year $t-2$ voting patterns have been compiled. Finally, as stressed in the 1997 version of the report to Congress, in recent years (1991 onwards) the US has successfully

\footnotetext{
${ }^{21}$ Data can be downloaded from www.columbia.edu/ eg589/datasets.htm.

${ }^{22}$ In the working paper version of the present paper we provide an alternative bliss-point proxy based only on non-key UNGA votes. As demonstrated therein, all results presented in this section carry through. This is not surprising, since the bulk of UNGA votes are non-key votes (see main text).
} 
accomplished that some voting issues will only be considered biannually in the UNGA. These observations suggest the inclusion of the first and second lag of key votes in (11). Since the value of $\alpha$ is unknown, we estimate it. From (11) we retrieve $\alpha$ by testing restrictions on the estimated coefficients on mkvote $_{i, t-1}$ and $\left(\right.$ kvote $_{i, t-2}-$ bliss $\left._{i, t-2}\right)$, respectively. ${ }^{23}$

Different political variables. At this stage it is useful to be completely clear about the political variables used in the empirical literature and the political payment variable, $p_{i, t}-b_{i, t}$, identified in our theoretical model. Thacker (1999) relies on UNGA key votes to calculate political proximity, $p_{i, t-1}$, and the change herein (i.e. movement), $p_{i, t}-p_{i, t-1}$. Both Barro and Lee (2002), Neumayer (2003), Oatley and Yackee (2000) and Stone (2004) all use (both key and non-key) UNGA votes in computing their political variable. The terminology differs widely across these studies; they use respectively proximity, similarity, alignment and foreign-policy preferences. As argued above (and by Stone, 2004), relying on all UNGA votes is a measure of policy preferences; i.e. is a proxy for bliss points, $b_{i, t}$. If our model is an adequate description of reality, both $p_{i, t}$ and $b_{i, t}$ should be included; and their difference is an indicator of political payment.

\subsubsection{Results}

Turning to estimations, results from the pooled logit model applied by Thacker (1999) are reported in Table 1. We only report results for the political variables; since we only include/remove political variables; results for the economic conditioning variables are (qualitatively) identical to those reported in Thacker. In all estimations, the dependent loan variable is measured in period $t$, whereas explanatory economic variables are lagged by one period, i.e. are measured in period $t-1$.

\footnotetext{
${ }^{23}$ Our results are not sensitive to how we include the bliss-point proxy. In fact, all our results hold with bliss points being proxied by the simple average bliss $_{i, t}=\sum_{\tau=t_{0}}^{t} S_{i, \tau} /\left(t-\left(t_{0}-1\right)\right)$, where $t$ runs from $t_{0}=1985$ to $T=1994$.
} 


\begin{tabular}{|c|c|c|c|c|c|c|}
\hline & (1) & $(2)$ & $(3)$ & $(4)$ & $(5)$ & $(6)$ \\
\hline \multirow[t]{2}{*}{ kvote $_{i, t-2}$} & 1.25 & & & & -0.93 & \\
\hline & $(1.74)^{*}$ & & & & $(1.43)$ & \\
\hline \multirow[t]{2}{*}{ kvote $_{i, t-1}$} & & & & & & 2.41 \\
\hline & & & & & & $(3.31)^{* * *}$ \\
\hline \multirow[t]{2}{*}{$m_{k v o t e} e_{i, t-1}$} & 2.76 & & & 1.18 & & \\
\hline & $(3.47)^{* * *}$ & & & $(1.48)$ & & \\
\hline \multirow[t]{2}{*}{$b i d_{i, t-1}$} & & 2.38 & 2.27 & 1.70 & 2.80 & \\
\hline & & $(3.27)^{* * *}$ & $(2.51)^{* *}$ & $(1.97)^{* *}$ & $(3.58)^{* * *}$ & \\
\hline \multirow[t]{2}{*}{ bliss $_{i, t-1}$} & & & & & & -3.34 \\
\hline & & & & & & $(1.71)^{*}$ \\
\hline \# obs. & 746 & 746 & 746 & 746 & 746 & 746 \\
\hline Pseudo R2 & 0.17 & 0.17 & 0.19 & 0.18 & 0.18 & 0.17 \\
\hline
\end{tabular}

Table 1. Pooled logit estimations from Thacker's baseline model. Notes: ${ }^{*},{ }^{* *}$ and $* * *$ denote significance at the 10,5, and 1 percent level, respectively. The model is dynamically complete so standard inference is valid (t-values in parentheses). The dependent variable is binary (=1 for a country year if the country received a SBA or an EFF loan during a calendar year). Economic conditioning variables include overall balance of payments, per capita overall balance of payments, current account balance, per capita debt, debt to GNP, interest payments to GNP, reserves to GNP, per capita GNP, previous cancellations of IMF programs, US exports, US FDI and first differences of these variables. All economic conditioning variables are lagged one period. Column (3) is estimated with time dummies; these are jointly insignificant. All economic data and key vote data are taken from Thacker (1999); that paper should be consulted for detailed information on data and definitions of the variables. Bliss points are calculated using data downloaded from www.columbia.edu/ eg589/datasets.htm. 
The first column, denoted (1), is the original baseline model proposed by Thacker. Proximity, $k v o t e_{i, t-1}$, is marginally significant whereas movement, mkvote $e_{i, t-1}$, is significant at one percent. In column (2) we have estimated the model with the restriction $\alpha=1$ in (11) imposed; we cannot reject this restriction at any significance level below 0.14. Column (2) is in fact the correct test of our theoretical model: We have a model based on optimizing behavior and column (2) demonstrates that the predictions of the model, i.e. that the probability of receiving an IMF loan is increasing in the amount of political payments, cannot be rejected by the data. ${ }^{24}$ Column (3) is column (2) with time dummies; these are jointly insignificant. ${ }^{25}$

Columns (4) and (5) demonstrate that movement, mkvote $_{i, t-1}$, and proximity, $k v o t e_{i, t-2}$, are irrelevant once $b i d_{i, t-1}$ is accounted for. One way to interpret these columns is as follows: We are trying to statistically choose between two nonnested models (Gourieroux and Monfort, 1994). Columns (4) and (5) are "supermodels" that artificially nest two competing models; one with $b i d_{i, t-1}$ (our model) and mkvote $e_{i, t-1}$ (column (4)) and one with bidit,-1 and $k_{v o t e} e_{i, t-2}$ (column (5)). In both columns, $b_{i, t-1}$ dominates. Our political variable $b i d_{i, t-1}$ is thus statistically preferred to mkvote $_{i, t-1}$ and $k v o t e_{i, t-2}$ in the sense that the last two turn insignificant, whereas $b i d_{i, t-1}$ is significant at five and one percent, respectively. This allows us to statistically choose $b i d_{i, t-1}$ over mkvote $e_{i, t-1}$ and $k v o t e_{i, t-2}$.

Column (6) reveals that it is not kvote $_{i, t-1}$ that drives our results since bliss $s_{i, t-2}$ comes with a statistically significant negative sign. ${ }^{26}$ Hence, a higher value of $b l i s s_{i, t-2}$, i.e. a tighter constraint on political payments, lowers the probability of receiving a loan. Intuitively, this is a sensible result since countries with high bliss points have a binding "bidding constraint"

\footnotetext{
${ }^{24}$ Simply using $\alpha=\frac{1}{2}$ does not change this conclusion.

${ }^{25}$ In column (2), the marginal effect on the loan probability of a marginal increase in bid (estimated at mean values of the independent variables) is 0.23 (the probability of an IMF loan at mean values is 0.11 and the mean bid is 0.35 ). The quasi-elasticity at mean values is 0.08 . Hence, an increase at mean values of one percent in bid leads to an increase in the loan probability of 0.08 percentage point (from $11 \%$ to $11.08 \%$ ).

${ }^{26} \mathrm{~A}$ Wald test cannot reject the restriction that the coefficients on $k v o t e_{i, t-1}$ and bliss $_{i, t-1}$ sum to zero at any significance level below 0.59 .
} 
more often. It would also be the prediction of the theoretical model in the two-country case when the countries have bliss points that are sufficiently far apart.

\subsubsection{Fixed-effects approach}

As mentioned above, another valid estimation approach is to rely on a fixed-effects panel estimator in order to eliminate the unobserved heterogeneity (unobserved bliss points). We have experimented with this (not reported) and results are fully consistent with our story. Briefly, instead of relying on a dynamically complete logit model as above (see Wooldridge, 2002 p. 483 for dynamic completeness), we have estimated a parsimonious conditional fixedeffects logit. As emphasized by Wooldridge (2002 p. 409), including sufficient lags in order to induce dynamic completeness is not necessarily desirable when unobserved heterogeneity is causing the serial correlation in the scores across time. We expect this to be the case when bliss points are omitted, and a Hausman test confirms the presence of unobserved heterogeneity. In the conditional fixed-effects logit $k v o t e_{i, t-1}$ is always significant, which is in line with $b i d_{i, t-1}$ being the relevant political variable.

\subsubsection{Country episodes}

Apart from the econometric analysis looking at a few country episodes is instructive. Only two countries received six IMF loans over the period 1985-1994: Jamaica and Ecuador; all other countries received fewer loans. Moreover, both Jamaica and Ecuador gave large political concessions to the US in the UNGA, with cumulative bids above the 75th percentile. Jamaica was forced by circumstances to approach the US. In particular, Michael Manley led the country towards democratic socialism (nationalizing industry and denouncing US imperialism) in the 1970s, causing capital flight and hyperinflation. The US was hostile to the socialist path Jamaica was embarking on; and when Manley became too friendly with Fidel Castro, rumors emerged that the CIA planned to topple him. The economy 
went into sharp decline. In 1980, Edward Seaga of the Jamaican Labor party won the election and inherited disarray. Seaga severed ties with Cuba and courted Reagan's USA. Interestingly, this happened at a time when Congress passed Public Laws 98-164 and 99190, which authorized the US President to withhold aid to countries that regularly cast votes against US positions in the UN (Wang, 1999). In 1989, a "reinvented" Manley returned to power, this time leading a much more moderate government. During Manley's second tenure (1989-1992), ${ }^{27}$ Jamaica received three IMF loans (in 1990, 1991 and 1992).

Twenty-three countries never received any IMF loans. Among these, Yemen and Fiji stand out: the former gave the smallest political concession among all sample countries; the latter gave the highest. Fiji does not seem to fit the model well. ${ }^{28}$ Other countries, e.g. Colombia, also gave large political concessions without receiving any IMF loans. For some of these countries, however, the non-fit is more apparent than real. Colombia, for instance, has received large amounts of US military aid to assist the Colombian government in the battle against drug trade (or the guerrillas, since these are intimately involved with narcotics trafficking). The US assistance goes back to the first Bush administration (1989-93) and its "Andean Strategy".

\subsection{Results from the post-1994 period}

In this section we test our hypothesis in a panel covering the period 1995 to 2000. Our dataset includes 177 IMF member countries, but our unbalanced estimation panel only includes 102 countries (539 country years and 62 loan spells). There are two reasons for this: First, we discarded 24 of the (presently) 30 OECD member countries; we have included Hungary,

\footnotetext{
${ }^{27}$ Manley resigned in 1992, citing health reasons.

${ }^{28}$ Israel, a staunch ally of the US and not part of the Thacker sample, did not receive any SBA or EFF IMF loans during the sample period. Israel had a bliss point of 0.91 in 1994, which effectively means that Israel had little to offer in terms of political concessions. In fact Israel only signed an IMF agreement in 1974, 1975 and 1976, which is well in accord with our theoretical model. Nevertheless,the US has given large amounts of strategic bilateral aid and military support to Israel over the years, without receiving any political concessions.
} 
Korea, Mexico, Poland, Slovak Republic and Turkey. ${ }^{29}$ Including all OECD countries simply inflates the fit of the empirical model. The reason is that the excluded OECD countries make small political concessions to the US and never receive IMF loans. Second, data availability caused another 51 countries to drop out of the panel. ${ }^{30}$ Following Bird and Rowlands (2001), we have addressed the problem that some countries were not eligible to sign an IMF agreement because of arrears to the Fund by simply including all countries. The argument is that the IMF could solve the arrears problem if it so wished by extending a new agreement.

We have estimated an empirical model along the lines of the baseline model reported in Thacker (1999). The model fits the data very well and underscores the continuity of the core argument pursued in this paper. Results are reported in Table 2. We will not discuss the economic conditioning variables in any detail (see Thacker, 1999). Nevertheless, a few issues deserve a brief comment. First, the signs of all variables that are statistically significant in Thacker's baseline model (see column 1, Table 1 in Thacker, 1999) and included in Table 2 (i.e., GNP per capita, balance of payments, debt to GNP, debt per capita, interest payments to GNP, both level and first difference, and reserves to debt) are preserved in Table 2. Second, among these economic variables, we also find that the balance of payments, debt to GNP and interest payments to GNP are statistically significant. Third, as in Thacker, we find a negative and statistically significant sign associated with the debt to GNP variable. Note, however, that this is counterbalanced by a positive and statistically significant sign on the absolute level of debt. Fourth, the change in the current account variable has an unexpected positive and statistically significant sign; this is, however, counterbalanced by the change in the current account to GNP variable, which is negative and statistically significant. Finally,

\footnotetext{
${ }^{29}$ Korea, however, drops out because the World Development Indicators (2004) provide no information on public and publicly guaranteed debt (the dt_dod_dppg_cd series) for Korea. However, none of the results reported below change if we use long-term debt outstanding and disbursed from Global Development Finance (2003) (the dt.dod.dlxf.cd series) for Korea instead.

${ }^{30}$ See Appendix A.4 for a list of countries included.
} 
the Asian crisis dummy has a negative and statistically significant effect on the probability of an IMF loan: large loans to a few hard hit countries squeezed IMF liquidity. 


\begin{tabular}{|c|c|c|c|}
\hline & $(1)$ & $(2)$ & $(3)$ \\
\hline & coefficient & quasi elasticity & \\
\hline GNP per capita & $\begin{array}{c}-0.018 \\
(0.73)\end{array}$ & & $\begin{array}{c}-0.019 \\
(0.72)\end{array}$ \\
\hline Balance of payments (BoP) & $\begin{array}{l}-0.012 \\
(3.62) * * *\end{array}$ & -0.001 & $\begin{array}{l}-0.010 \\
(2.85) * *\end{array}$ \\
\hline$\Delta(\mathrm{BoP})$ & $\begin{array}{l}-0.010 \\
(2.12) * *\end{array}$ & $-1.7 \cdot 10^{-4}$ & $\begin{array}{l}-0.010 \\
(1.89) *\end{array}$ \\
\hline BoP per capita & $\begin{array}{l}0.164 \\
(1.00)\end{array}$ & & $\begin{array}{l}0.110 \\
(0.63)\end{array}$ \\
\hline$\Delta($ BoP per capita $)$ & $\begin{array}{l}0.069 \\
(0.38)\end{array}$ & & $\begin{array}{l}0.048 \\
(0.25)\end{array}$ \\
\hline Current account & $\begin{array}{l}0.002 \\
(0.50)\end{array}$ & & $\begin{array}{l}0.001 \\
(0.28)\end{array}$ \\
\hline$\Delta$ (Current account $)$ & $\begin{array}{c}0.013 \\
(2.93) * * *\end{array}$ & 0.001 & $\begin{array}{c}0.014 \\
(3.11) * * *\end{array}$ \\
\hline Current account/GNP & $\begin{array}{c}-0.565 \\
(0.19)\end{array}$ & & $\begin{array}{l}0.569 \\
(0.17)\end{array}$ \\
\hline$\Delta($ Current account/GNP $)$ & $\begin{array}{l}-6.661 \\
(2.04) * *\end{array}$ & -0.001 & $\begin{array}{l}-6.213 \\
(1.83) *\end{array}$ \\
\hline Debt & $\begin{array}{l}0.001 \\
(2.29) * *\end{array}$ & 0.008 & $\begin{array}{l}0.002 \\
(2.13) * *\end{array}$ \\
\hline$\Delta($ debt $)$ & $\begin{array}{l}0.007 \\
(0.62)\end{array}$ & & $\begin{array}{l}0.007 \\
(0.66)\end{array}$ \\
\hline Debt/GNP & $\begin{array}{l}-2.968 \\
(2.91) * * *\end{array}$ & -0.076 & $\begin{array}{l}-3.562 \\
(2.68) * * *\end{array}$ \\
\hline$\Delta($ debt $/$ GNP $)$ & $\begin{array}{l}1.944 \\
(0.75)\end{array}$ & & $\begin{array}{l}1.913 \\
(0.78)\end{array}$ \\
\hline Debt per capita & $\begin{array}{l}0.073 \\
(1.52)\end{array}$ & & $\begin{array}{l}0.064 \\
(1.31)\end{array}$ \\
\hline$\Delta($ Debt per capita $)$ & $\begin{array}{c}-0.114 \\
(0.81)\end{array}$ & & $\begin{array}{c}-0.108 \\
(0.80)\end{array}$ \\
\hline Interest payments/GNP & $\begin{array}{l}0.271 \\
(1.73) *\end{array}$ & 0.024 & $\begin{array}{l}0.284 \\
(1.84) *\end{array}$ \\
\hline$\Delta($ Interest payments/GNP $)$ & $\begin{array}{l}0.505 \\
(1.53)\end{array}$ & & $\begin{array}{l}0.489 \\
(1.53)\end{array}$ \\
\hline Reserves/debt & $\begin{array}{c}-0.001 \\
(0.41)\end{array}$ & & $\begin{array}{c}-0.001 \\
(0.33)\end{array}$ \\
\hline$\Delta($ Reserves/debt $)$ & $\begin{array}{c}-0.002 \\
(0.70)\end{array}$ & & $\begin{array}{c}-0.002 \\
(0.76)\end{array}$ \\
\hline
\end{tabular}


Table continued

\begin{tabular}{lccc}
\hline \hline & $(1)$ & $(2)$ & $(3)$ \\
\cline { 2 - 4 } & coefficient & quasi elasticity & \\
\hline kvote $_{i, t-2}$ & & & 4.926 \\
bid $_{i, t-1}$ & 4.386 & 0.028 & \\
bliss $_{i, t-2}$ & $(3.47) * * *$ & & \\
& & & -2.970 \\
Asian crisis dummy & -1.706 & -0.013 & $(1.91) *$ \\
& $(2.44) * * *$ & & $(2.47) * * *$ \\
Constant & -2.533 & & -3.570 \\
& $(3.48) * * *$ & & $(3.35) * * *$ \\
Number of observations & 539 & & 539 \\
Pseudo R2 & 0.23 & & 0.24 \\
Correctly predicted (\%) & 89.42 & & 88.87 \\
\hline \hline
\end{tabular}

Table 2. Logit Estimations (1995-2000). Notes: *, ** and *** denote significance at the 10, 5, and 1 percent level, respectively (t-statistics robust to arbitrary heteroscedasticity and arbitrary serial correlation across time in parentheses). The dependent variable is binary (=1 for a country year if the country signed a SBA or an EFF loan agreement during the calendar year). All economic conditioning variables are lagged one period. Economic level variables are in millions of 1999 USD; per capita economic variables are in 1999 USD. Economic data are taken from IMF Annual Report (various years), IMF International Financial Statistics (2002) and World Development Indicators (2004). The GDP deflator is from OECD International Development Statistics (2003). Bliss points are calculated using data downloaded from www.columbia.edu/ eg589/datasets.htm (values for 1997 and 1998 are extrapolated from 1996). Key votes are obtained from the annual report to Congress on "Voting Practices in the United Nations" (various years) prepared by the United States Department of State.

Column (1) estimates bid $_{i, t-1}$ as described by equation (11) with the restriction $\alpha=0$ imposed. A Wald test cannot reject this restriction at any significance level below 0.21. Column (1) is the correct test of our hypothesis. Importantly, we cannot reject our model at one percent in this updated dataset. ${ }^{31}$

\footnotetext{
${ }^{31}$ Results are robust with respect to the choice of $\alpha$. For instance, $b i d_{i, t-1}$ retains significance at one percent with $\alpha=\frac{1}{2}$ and at ten percent with $\alpha=\frac{9}{10}$.
} 
Column (2) reports quasi elasticities at mean values (indicating the percentage point change of the probability upon a $1 \%$ increase in an independent variable) for the statistically significant variables. The probability of an IMF loan at mean values is $4.473 \%$ and the mean value of $b i d_{i, t-1}$ is 0.147 . Hence, a increase in $b i d_{i, t-1}$ from 0.147 to 0.148 will roughly increase the probability of an IMF loan with 0.028 percentage point (from $4.473 \%$ to $4.501 \%$ ), implying economic significance. The following example shows economic significance in terms of a one-key vote change in voting behavior:

Example 6 Consider a situation with 10 key votes; and consider a country with a bliss point of 0.45 (roughly the sample average), which votes with the US on 6 key votes and abstain on the rest. The bid is then $0.6-0.45=0.15$. If the country now changes voting behavior and chooses to vote with the US on 7 key votes, it increases the bid to $0.7-0.45=0.25$. This translates into an increase in the probability of an IMF loan of roughly 1.87 percentage point (at mean values).

Column (3) demonstrates that bliss $_{i, t-2}$ is marginally significant with a negative sign, which is in full accord with column (6) in Table 1. That is, a higher bliss point implies that the "bidding constraint" will bind more often. Moreover, a Wald test cannot reject the restriction that the coefficients on kvote $_{i, t-2}$ and $b_{i s s_{i, t-2}}$ sum to zero at any significance level below 0.15 percent.

\subsubsection{Other issues (including robustness)}

Loan size. Our theoretical model makes no predictions regarding the size of the loan; it only makes predictions regarding the probability of receiving an IMF loan. We have, however, experimented with a tobit model. It turns out that a tobit model is inappropriate in the present context. A tobit model forces the probability of a loan to be governed by the same mechanism that governs the size of a loan. Wooldridge (2003) outlines a simple 
(informal) test of this assumption; a tobit in the present context fails this test. ${ }^{32}$ We have therefore also experimented with a hurdle model (see Wooldridge, 2002), but an effect from $b i d_{i, t-1}$ to loan size was not found.

Other political variables. We have experimented with other political variables. For instance, we have included a variable in column (1) (not reported), which measures richcountry influence more broadly; it is a DAC weighted version of the Signorino and Ritter (1999) measure. Each country's voting similarity with the individual DAC donors is first calculated according to the Signorino and Ritter formula. These numbers are then weighted by the proportion of total DAC aid provided by each of the individual donors so as to obtain a single measure of DAC-weighted voting similarity. This measure has no explanatory power when $b i d_{i, t-1}$ is included, while $b i d_{i, t-1}$ retains significance at one percent. Moreover, the DAC weighted measure also has no explanatory power when $b i d_{i, t-1}$ is excluded.

We have also estimated column (1) with the inclusion of a variable measuring the sum of NATO arms exports in the period 1992-1997. This variable has some explanatory power. It has a statistically significant effect on the probability of an IMF loan at ten percent; the quasi elasticity is $0.001 .^{33}$ The $b i d_{i, t-1}$ variable remains significant at one percent with a coefficient of 4.47 and with the exact same quasi elasticity (at mean values) as above, i.e. 0.028. Interestingly, when $b i d_{i, t-1}$ is excluded, the sum of NATO arms exports in the period 1992-1997 looses significance.

Finally, we have estimated the model with a variable measuring the amount an IMF member country imports from the G7 countries. ${ }^{34}$ This variable had no explanatory power.

\footnotetext{
${ }^{32}$ One explanation may be that countries with really poor fundamentals are more likely to receive a loan compared to countries with better fundamentals, but at the same time, conditional on receiving a loan, the former countries receive smaller loans compared to countries with better fundamentals. The Asian Crisis, for instance, involved large loans to countries with relatively good fundamentals (Tirole, 2002). This violates the assumptions behind the tobit model.

${ }^{33}$ However, it looses significance when Korea is included.

${ }^{34}$ These variables were compiled by Eric Neumayer (2003). We thank him for kindly making his data available.
} 
Consequently, adding other measures of political influence does not have any implications for the significance (statistical and economic) of the $b i d_{i, t-1}$ variable.

Other IMF loan arrangements. If we, in addition to SBA loans and EFF loans, also include ESAF loans (not reported), $b i d_{i, t-1}$ retains significance at one percent with a coefficient estimate of 2.55. ${ }^{35}$ However, the overall fit of the model drops dramatically: the pseudo R2 becomes 0.08. The reduction in explanatory power hides an interesting observation: With ESAF loans as the only dependent variable, $b i d_{i, t-1}$ is no longer significant. The single most important variable in explaining ESAF lending is GDP per capita. Thus, political factors do not seem to influence ESAF lending.

\section{Conclusion}

IMF lending to developing countries is controversial. Case studies and some econometric evidence are available, especially on the economic determinants of IMF behavior. Yet much remains to be learned about how economic and political factors shape IMF decision making. Also, since formal modelling of the political economy in which this international organization finds itself is scant, proper interpretation of results from empirical work is not straightforward.

In this paper, we put forward a stylized model of US influence on IMF lending. Assuming that the US wishes to maximize its overall influence on the policy stance of debtor countries, we derived an optimal loan allocation mechanism and articulated a testable hypothesis. It states that the probability of receiving an IMF loan is increasing in political payments, defined as the difference between a given country's actual policy stand and its true political preferences (i.e. its bliss point) measured relative to the US.

\footnotetext{
${ }^{35}$ In September 1999, the Poverty Reduction and Growth Facility (PRGF) replaced the Enhanced Structural Adjustment facility (ESAF).
} 
The model highlights that leaving bliss points unaccounted for (which to our knowledge is the case in previous work) may hide an endogeneity problem. We introduced a bliss-point proxy and tested our model using two panels. The data support the claim that the US influences how the Fund allocates its loans in a manner which is consistent with our model.

In sum, in this paper we put focus on the need to take account of true political preferences of member countries in their relationship with the US. Moreover, by capturing such preferences explicitly through a bliss-point proxy, we believe to have strengthened the view that political factors, in this case US politics, play a decisive role in IMF decision making. 


\section{A Appendix}

\section{A.1 Proof of Lemma 1}

Take any mechanism $\left\langle\left(x_{i}\left(\theta_{i}, \theta_{-i}\right)\right), t_{i}^{W}\left(\theta_{i}, \theta_{-i}\right), t_{i}^{L}\left(\theta_{i}, \theta_{-i}\right)\right\rangle_{i \in \mathcal{N}}$ satisfying (2), (3), (4) and (5). We take the perspective of country $i$, noting that the argument is symmetric for other countries. For any $\theta_{i}$, define $t_{i}\left(\theta_{i}\right)$ as

$$
t_{i}\left(\theta_{i}\right) \equiv E_{\theta_{-i}}\left[x_{i}\left(\theta_{i}, \theta_{-i}\right) t_{i}^{W}\left(\theta_{i}, \theta_{-i}\right)+\left(1-x_{i}\left(\theta_{i}, \theta_{-i}\right)\right) t_{i}^{L}\left(\theta_{i}, \theta_{-i}\right)\right] .
$$

We will argue that $\left\langle\left(x_{i}\left(\theta_{i}, \theta_{-i}\right)\right), t_{i}\left(\theta_{i}\right)\right\rangle_{i \in \mathcal{N}}$ is a feasible direct mechanism. This requires that

$$
\begin{gathered}
E_{\theta_{-i}}\left[x_{i}\left(\theta_{i}, \theta_{-i}\right)\right] \theta_{i}-t_{i}\left(\theta_{i}\right) \geq E_{\theta_{-i}}\left[x_{i}\left(\theta_{i}^{\prime}, \theta_{-i}\right)\right] \theta_{i}-t_{i}\left(\theta_{i}^{\prime}\right), \\
E_{\theta_{-i}}\left[x_{i}\left(\theta_{i}, \theta_{-i}\right)\right] \theta_{i}-t_{i}\left(\theta_{i}\right) \geq 0 \\
t_{i}\left(\theta_{i}\right) \leq w_{i},
\end{gathered}
$$

where $w_{i}=1-b_{i}$. Since (12) is equivalent to (2) and (13) is equivalent to (3), (12) and (13) are satisfied. Moreover, since $t_{i}^{W}\left(\theta_{i}, \theta_{-i}\right)$ and $t_{i}^{L}\left(\theta_{i}, \theta_{-i}\right)$ satisfy $(5), t_{i}\left(\theta_{i}\right)$ satisfies (14).

Weak dominance of the all-pay mechanism follows immediately from the fact that $t_{i}\left(\theta_{i}\right)$ is a convex combination of $t_{i}^{W}\left(\theta_{i}, \theta_{-i}\right)$ and $t_{i}^{L}\left(\theta_{i}, \theta_{-i}\right)$. That is, payment constraints bind less frequently in all-pay mechanisms. 


\section{A.2 Proof of Proposition 2}

Since $\max b_{i} \leq 1-\bar{\theta} \Leftrightarrow \min w_{i} \geq \bar{\theta}$, (8) implies that (10) is never violated. The optimal mechanism is then the solution to the problem (6) to (9), which is solved in Krishna (2002). Using the fact that valuations are i.i.d., Proposition 5.3 in Krishna gives that an optimal mechanism is a standard second-price auction. By the revenue equivalence theorem (see Krishna, Proposition 5.2), the all-pay auction is also an optimal mechanism. 


\section{A.3 Numerical solution}

The problem to be solved in Section 2.2.1 is:

$$
\max _{x_{i}\left(\theta_{1}, \theta_{2}\right), t_{i}\left(\theta_{i}\right)} \nu t_{1}(\bar{\theta})+(1-\nu) t_{1}(\underline{\theta})+\nu t_{2}(\bar{\theta})+(1-\nu) t_{2}(\underline{\theta})
$$

subject to

$$
\begin{gathered}
\bar{\theta}\left(\nu x_{1}(\bar{\theta}, \bar{\theta})+(1-\nu) x_{1}(\bar{\theta}, \underline{\theta})\right)-t_{1}(\bar{\theta}) \geq \bar{\theta}\left(\nu x_{1}(\underline{\theta}, \bar{\theta})+(1-\nu) x_{1}(\underline{\theta}, \underline{\theta})\right)-t_{1}(\underline{\theta}) \\
\underline{\theta}\left(\nu x_{1}(\underline{\theta}, \bar{\theta})+(1-\nu) x_{1}(\underline{\theta}, \underline{\theta})\right)-t_{1}(\underline{\theta}) \geq \underline{\theta}\left(\nu x_{1}(\bar{\theta}, \bar{\theta})+(1-\nu) x_{1}(\bar{\theta}, \underline{\theta})\right)-t_{1}(\bar{\theta}) \\
\bar{\theta}\left(\nu x_{2}(\bar{\theta}, \bar{\theta})+(1-\nu) x_{2}(\underline{\theta}, \bar{\theta})\right)-t_{2}(\bar{\theta}) \geq \bar{\theta}\left(\nu x_{2}(\bar{\theta}, \underline{\theta})+(1-\nu) x_{2}(\underline{\theta}, \underline{\theta})\right)-t_{2}(\underline{\theta}) \\
\underline{\theta}\left(\nu x_{2}(\bar{\theta}, \underline{\theta})+(1-\nu) x_{2}(\underline{\theta}, \underline{\theta})\right)-t_{2}(\underline{\theta}) \geq \underline{\theta}\left(\nu x_{2}(\bar{\theta}, \bar{\theta})+(1-\nu) x_{2}(\underline{\theta}, \bar{\theta})\right)-t_{2}(\bar{\theta}) \\
\bar{\theta}\left(\nu x_{1}(\bar{\theta}, \bar{\theta})+(1-\nu) x_{1}(\bar{\theta}, \underline{\theta})\right)-t_{1}(\bar{\theta}) \geq 0 \\
\underline{\theta}\left(\nu x_{1}(\underline{\theta}, \bar{\theta})+(1-\nu) x_{1}(\underline{\theta}, \underline{\theta})\right)-t_{1}(\underline{\theta}) \geq 0 \\
\bar{\theta}\left(\nu x_{2}(\bar{\theta}, \bar{\theta})+(1-\nu) x_{2}(\underline{\theta}, \bar{\theta})\right)-t_{2}(\bar{\theta}) \geq 0 \\
\underline{\theta}\left(\nu x_{2}(\bar{\theta}, \underline{\theta})+(1-\nu) x_{2}(\underline{\theta}, \underline{\theta})\right)-t_{2}(\underline{\theta}) \geq 0 \\
\min \left\{x_{i}(\bar{\theta}, \bar{\theta}), x_{i}(\bar{\theta}, \underline{\theta}), x_{i}(\underline{\theta}, \bar{\theta}), x_{i}(\underline{\theta}, \underline{\theta})\right\} \geq 0, \quad(\text { for } i=1,2) \\
x_{1}\left(\theta_{1}, \theta_{2}\right)+x_{2}\left(\theta_{1}, \theta_{2}\right) \leq 1 \quad\left(\text { for all }\left(\theta_{1}, \theta_{2}\right) \in\{\underline{\theta}, \bar{\theta}\} \times\{\underline{\theta}, \bar{\theta}\}\right) \\
\max \left\{t_{i}(\bar{\theta}), t_{i}(\underline{\theta})\right\} \leq w_{i}, \quad(\text { for } i=1,2) .
\end{gathered}
$$

The above mechanism design problem is a linear programming problem, which may have multiple solutions. In order to explore whether there always exists an optimal auction-type mechanism satisfying definition 4 , we undertook a systematic numerical analysis. For $\underline{\theta}=0.3$ and $\bar{\theta}=0.7$ we did numerical optimizations on 28,000 parameter combinations $\left(w_{1}, w_{2}, v\right)$, 
where $\left(w_{1}, w_{2}, v\right) \in[0,1]^{3}$. Specifically, $v \in[0.01,1]$ with a grid of $0.01 ; w_{1} \in\left[0.01, w_{2}\right]$ with a grid of 0.01 ; and $w_{2} \in[0.1,0.7]$ with a grid of 0.1 . First, we solved the linear program. Second, we imposed definition 4 as a nonlinear restriction and solved this constrained nonlinear optimization problem. Third, value functions were compared with an absolute tolerance of $1 \cdot 10^{-10}$. Differences between value functions were within the tolerance band in 97.38 percent of the cases. ${ }^{36}$

\footnotetext{
${ }^{36}$ We used linprog and fmincon in Matlab's optimization toolbox in the numerical study.
} 


\section{A.4 Sample countries}

Albania, Angola, Argentina, Armenia, Azerbaijan, Bangladesh, Belarus, Belize, Benin, Bolivia, Botswana, Brazil, Burundi, Cambodia, Cameroon, Cape Verde, Chile, China, Colombia, Comoros, Congo Rep., Costa Rica, Cote d'Ivoire, Croatia, Dominican Republic, Ecuador, Egypt, El Salvador, Eritrea, Estonia, Ethiopia, Fiji, Gabon, Gambia, Georgia, Ghana, Guinea, Guinea-Bissau, Guatemala, Guyana, Haiti, Honduras, Hungary, India, Indonesia, Jamaica, Jordan, Kazakhstan, Kenya, Kyrgyz Republic, Lao PDR, Latvia, Lesotho, Lithuania, Macedonia (FYR), Madagascar, Malawi, Malaysia, Mali, Mauritania, Mauritius, Mexico, Moldova, Mongolia, Morocco, Mozambique, Nepal, Nicaragua, Niger, Nigeria, Oman, Pakistan, Panama, Paraguay, Peru, Philippines, Poland, Russian Federation, Rwanda, Senegal, Sierra Leone, Slovak Republic, Solomon Islands, South Africa, Sri Lanka, St. Lucia, St. Vincent and the Grenadines, Sudan, Swaziland, Tanzania, Thailand, Togo, Turkmenistan, Trinidad and Tobago, Tunisia, Turkey, Uganda, Uruguay, Vanuatu, Venezuela, Vietnam, Zambia. 


\section{References}

[1] Barro, R. and Lee, J. (2002). 'IMF Programs: Who is Chosen and What are the Effects' NBER Working paper 8951.

[2] Bird, G. (1995). 'IMF Lending to Developing Countries: Issues and Evidence' London, Routledge.

[3] Bird, G. (1996). 'Borrowing from the IMF: The Policy Implications of Recent Empirical Research' World Development, 24, 1753-1760.

[4] Bird, G. and Rowlands, D. (2001). 'IMF Lending: How is it Affected by Economic, Political and Institutional Factors' Journal of Policy Reform 4, 243-270.

[5] Bird, G. and Rowlands, D. (2003). 'Political Economy Influences within the Life-Cycle of IMF Programmes', World Economy 26, 1255-1278.

[6] Calomiris, C. (2000). 'When Will Economics Guide IMF and World Bank Reforms?' Cato Journal, 20, 85-103.

[7] Dreher, A. and Jensen, N. (2004). 'Independent Actor or Agent? An Empirical Analysis of the Impact of US Interests on IMF Conditions', Leitner Working Paper 2003-04, Leitner Program in International Political Economy, Yale University.

[8] Gartzke, E. and Jo, D.-J. (2002). 'The Affinity of Nations Index, 1946-1996', Version 3.0, www.columbia.edu/ $\sim$ eg589/datasets.htm.

[9] Goldstein, M. and Montiel, P. (1986). Evaluating Fund Stabilization Programs with Multicountry Data: Some Methodological Pitfalls, IMF Staff Papers, 33, 304-344.

[10] Gould, E. (2003). Money Talks: Supplementary Financiers and International Monetary Fund Conditionality, International Organization, 57, 551-586. 
[11] Gourieroux, C. and Monfort, A. (1994). 'Testing Non-Nested Hypothesis' In Z. Griliches and M. Intriligator, eds., Handbook of Econometrics, Vol. 4., North Holland.

[12] Killick, T., 1995. IMF Programs in Developing Countries: Design and Impact, London, Routledge.

[13] Knight, M. and Santealla, J. (1997). 'Economic Determinants of IMF Financial Arrangements' Journal of Development Economics, 54, 405-436.

[14] Krishna, V. (2002). 'Auction Theory'. Academic Press.

[15] Laffont, J. and Robert, J. (1996). 'Optimal Auction with Financially Constrained Buyers' Economics Letters, 52, 181-186.

[16] Maskin, E. (2000). 'Auctions, Development, and Privatization: Efficient Auctions with Liquidity-Constrained Buyers' European Economic Review, 44, 667-681.

[17] Meltzer Commission (2000). 'The International Financial Institution Advisory Commission' www.bicusa.org/usgovtoversight/meltzer.htm

[18] Myerson, R. (1981). 'Optimal Auction Design' Mathematics of Operations Research, 6, 58-73.

[19] Neumayer, E. (2003). 'The Pattern of Aid Giving', Routledge.

[20] Oatley, T. and Yackee, J. (2000). 'Political Determinants of IMF Balance of Payments Lending: The Curse of Carabosse' University of North Carolina, Mimeo.

[21] Signorino, C. and Ritter, J. M. (1999). 'Tau-b or Not Tau-b: Measuring the Similarity of Foreign Policy Positions', International Studies Quarterly, 43, 115-144.

[22] Stone, R. (2002). 'Lending Credibility: The International Monetary Fund and the PostCommunist Transition' Princeton University Press. 
[23] Stone, R. (2004). 'The Political Economy of IMF Lending in Africa', American Political Science Review, 98, 577-591.

[24] Thacker, S. (1999). 'The High Politics of IMF Lending', World Politics, 52, 38-75.

[25] Tirole, J. (2002). 'Financial Crisis, Liquidity, and the International Monetary System', Princeton University Press.

[26] US State Department (various years). 'Report to Congress on Voting Practices in the United Nations'. Washington, D.C..

[27] Wang, T. (1999). 'U.S. Foreign Aid and UN Voting: An Analysis of Important Issues', International Studies Quarterly, 43, 199-210.

[28] Wooldridge, J. (2002). 'Econometric Analysis of Cross Section and Panel Data', The MIT Press.

[29] Wooldridge, J. (2003). 'Introductory Econometrics', Thomson South-Western Publishers. 

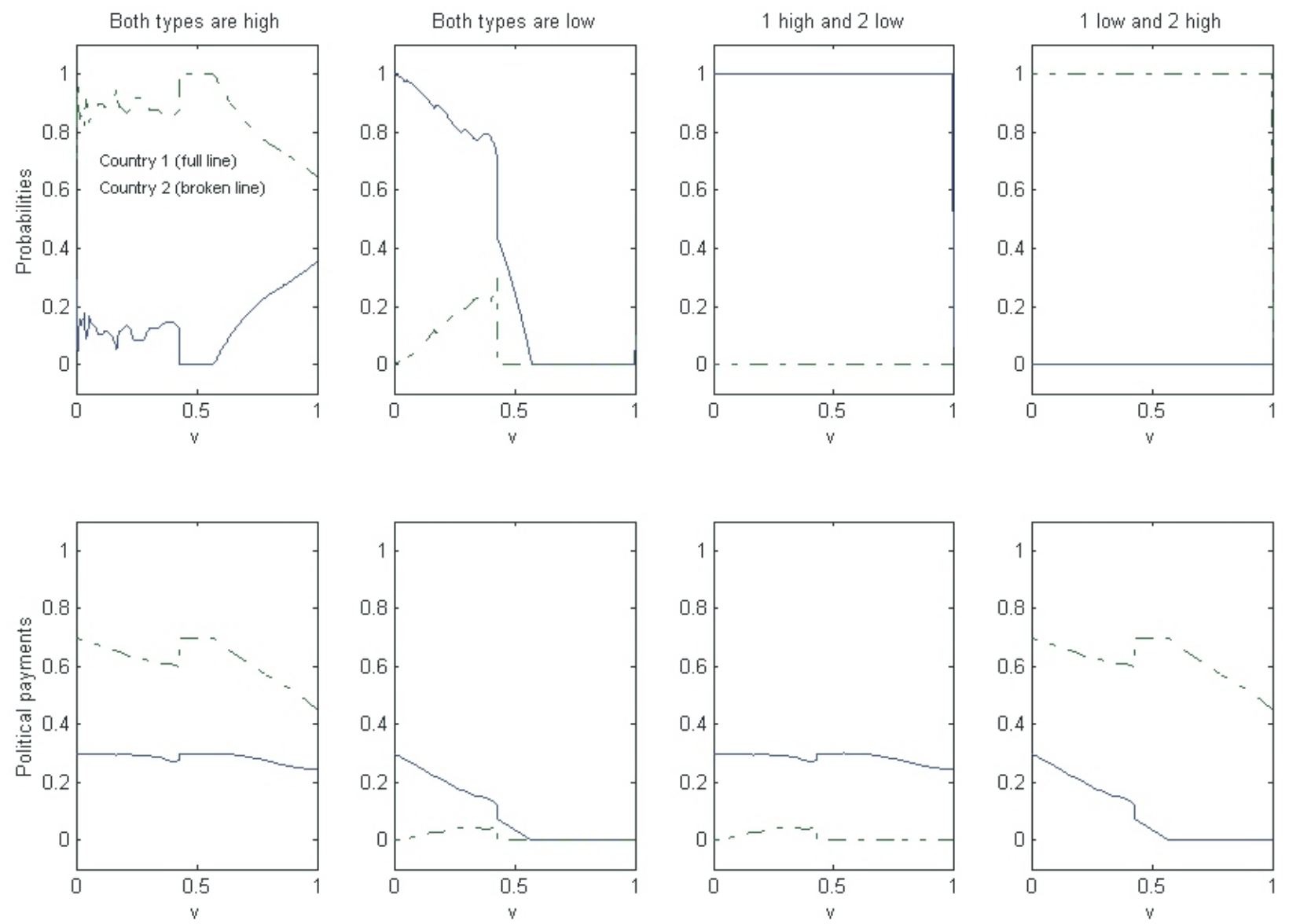

Fig. 2 


\section{Revision of EER-D-04-00836 Authors' response to Referee \#1:}

\section{Issue 1:}

The referee finds the paper could achieve more, especially if we: (i) bring the data up-to-date; (ii) test for other forms of G7 influence; and (iii) try using other dependent variables (loan size and the degree of conditionality). The referee would also like to see how political influence over the IMF has changed, if at all, in the post-1994 period. The referee urges us to discuss this even if we do not bring our empirical analysis up-to-date.

\section{Answer:}

(i) We fully agree with the referee that an updating of the dataset is both relevant and of interest. The reason for focusing squarely on the Thacker dataset in the first place was to try to avoid the objection that our key result is caused by differences in data and/or model specification. To respond in an appropriate manner to the referee and at the same time take account of this concern, we retain the independent analysis of the Thacker dataset, while providing as well a complete empirical analysis of the period 1995 to 2000. Our results are as shown in the new Section 3.2 fully consistent between the two periods. Undertaking the suggested additional work has also in our view strengthened the paper considerably.

(ii) We have tested as well (see Section 3.2.1) for other forms of G7 influence. In particular, we have added a DAC weighted UN voting variable, a variable capturing NATO arms export and a G7 import variable. All are used by Eric Neumayer (2003). Adding such variables does not alter our key result, but we recognize that this additional testing was very useful to put focus on the robustness of our findings.

(iii) Concerning the use of other dependent variables such as loan size (raised by both referees) and the degree of conditionality, it is important to highlight that our theoretical model is silent on this. The theoretical model only addresses the probability of receiving an IMF loan. That being said, we have - to respond in a proper way to the referees - tested for loan size as reported in Section 3.2.1. This empirical analysis suggests that the mechanism determining the allocation of loans (i.e. who gets a loan) is different from the mechanism determining the size of a loan. This means that a tobit model cannot be used to analyze loan size. Hence, we have also experimented with a hurdle model, but have not been able to detect any link from bid to the size of the loan. Concerning the degree of conditionality we now mention a recent paper by Dreher and Jensen (2004) on this issue.

\section{Issue 2:}

The referee would like us to consider whether the exclusion of ESAF loans is likely to make a difference to our results. The referee expects the inclusion of ESAF loans to make a difference.

\section{Answer:}

We have estimated a model in which ESAF loans are included. The intuition of the referee is absolutely correct. The inclusion of ESAF loans does make a difference. We have therefore included a discussion of this in Section 3.2.1.

\section{Issue 3:}

The referee would like us to consider which mechanism the US Dept. of State uses for determining key votes. 
Answer:

The report to Congress is addressed to the President of the Senate and to the Speaker of the House of Representatives, and it is signed by the Secretary of State. Ultimately, it is the Secretary of State, who endorses the identification of key votes. As such we find it justified to rely on key votes as done in our paper. Moreover, we have noted in the revised paper that key votes concern really crucial foreign policy issues for the US. In fact, many of the key votes are the same from year to year (e.g. the trade embargo of Cuba, Israeli nuclear armament and issues concerning North Korea and Iraq).

\section{Issue 4:}

The referee would like us to consider whether other measures of US interests would give similar results.

\section{Answer:}

We have tested for the influence of other US political interest variables such as US export in general and US arms export in particular (both compiled by Eric Neumayer). They have no explanatory power neither when used on their own nor when bid is included (while bid is always significant at one percent). This suggests that key votes, which is a US political-interest variable sanctioned by the US Secretary of State, is indeed a powerful and well-defined core explanatory (political) variable. We also note that outgoing US FDI (a variable used by Thacker) has no influence neither when used on its own nor when bid is included (while bid is always significant at one percent).

In sum, we agree with the excellent and useful comments by the referee and have tried to address them in a comprehensive manner. Undertaking the additional work suggested was certainly worth it with a view to completing a more comprehensive and satisfactory paper. 


\section{Revision of EER-D-04-00836 Authors' response to Referee \#2:}

\section{Issue 1:}

The referee senses that the importance of political payments is perhaps too much emphasized in the paper, and the referee is unsure why only political payment is important but 'political proximity' is not important at all. The referee suggests that Israel provides a case in point and that the results from fixed-effects estimations point in the same direction. The referee urges that we provide a careful discussion of this point. Moreover, the referee finds it strange that the sample of the regressions excludes Israel as well as all industrial countries.

\section{Answer:}

We agree with the referee that these points needed to be better explained. This we have done in the revised version as follows:

First, we have clarified that proximity (as defined by Thacker) does indeed matter, but in conjunction with bliss points; and our results strongly suggest that the political payment approach is the correct model. In fact, the bid variable is preferred in both the Thacker sample and in the 19952000 sample. Moreover, results from the fixed-effects estimator are fully consistent with this. We have a theoretical model saying that if we only include proximity, we leave out a fixed-effect (bliss points), which is correlated with proximity. A Hausman test cannot reject the presence of fixed effects, and proximity is significant with the correct sign. In addition, we have clarified in Section 3.1.1 the different concepts of proximity used in the literature.

Second, Israel did not receive any SBA and EFF IMF loans during the Thacker sample years. Moreover, it did not receive any loans in the extended sample period from 1995 to 2000. It is true that Israel's bliss point is close to one. In an IMF context, this means that Israel fits our model perfectly: low bids - no loans. This same is true for the other industrial countries; they have all made low bids and received no loans. As such, if we had included these countries it would simply increase the fit of the model; but it would not provide any interesting econometric information. Nevertheless, we recognize that the US has given large amounts of strategic bilateral aid and military support to Israel over the years, without receiving any political concessions. Israel has received lots of US military assistance during the years without giving political concessions; this is related to the exceptional role of Israel in the broader Middle Eastern context.

\section{Issue 2:}

The referee would like us to provide a few country episodes to explain the importance of bliss points and political concessions. The referee recommends that we shed light on which country provided the highest political concessions to the US over time and got IMF loans more frequently?

\section{Answer:}

We fully agree that a discussion of some country episodes is interesting. Moreover, we find the referee's suggestion very useful, and therefore have included discussion of a few country episodes in Section 3.1.4 without expanding the size of the paper too much.

\section{Issue 3:}

The referee would like us to explain how the IMF loan variable treats multi-year programs. 
Answer:

We agree that not commenting on this was an omission and have now included a note on this issue in Section 3.1.

\section{Issue 4:}

The referee asks whether the empirical model can be extended to explain the size of IMF loans.

Answer:

Both referees have raised this interesting question. Our theoretical model is silent on this point; it only addresses the loan allocation issue. That being said, we have - to respond in a proper way to the referees - tested for loan size as reported in Section 3.2.1. This empirical analysis suggests that the mechanism determining the allocation of loans (i.e. who gets a loan) is different from the mechanism determining the size of a loan. This means that a tobit model cannot be used to analyze loan size. Hence, we have also experimented with a hurdle model, but have not been able to detect any link from bid to the size of the loan.

In sum, we are most grateful for the pertinent comments by the referee and have tried to address them in a comprehensive manner. We believe this has strengthened the paper. 